\title{
Journal of Cleaner Production
}

Volume 244, 20 January 2020, 118675

\section{Effect of Organic Matter Release from Natural Cork Used on Bisphenol A Removal}

\section{from Aqueous Solution}

Carla Pirozzi ${ }^{\mathrm{a}, \mathrm{b}}$, Ludovico Pontoni ${ }^{\mathrm{a}}$, Massimiliano Fabbricino ${ }^{\mathrm{a}}$, Anna Bogush ${ }^{\mathrm{c}}$, Luiza C.

Campos $^{b^{*}}$

a Department of Civil Architectural and Environmental Engineering - University of Naples

Federico II Via Claudio 21 - 80125 Naples, Italy

${ }^{\mathrm{b}}$ Department of Civil, Environmental and Geomatic Engineering, University College London,

Chadwick Building, Gower Street, WC1E 6BT London, United Kingdom

${ }^{\mathrm{c}}$ Department of Earth Sciences, University College London, Chadwick Building, 5 Gower

Place, WC1E 6BS London, United Kingdom

* Corresponding author: 1.campos@ucl.ac.uk

Email addresses: carla-pirozzi@ hotmail.com (Pirozzi, C.), ludovico.pontoni@unina.it

(Pontoni, L.) massimiliano.fabbricino@gmail.com (Fabbricino, M.), a.bogush@ucl.ac.uk

(Bogush, A.) 1.campos@ucl.ac.uk (Campos, L.C.) 


\begin{abstract}
The paper presents an experimental study aimed at investigating the mechanism responsible for Bisphenol A adsorption on natural cork, and the role played on process kinetics by the organic matter released from the cork. Obtained data show that natural cork has a good affinity toward Bisphenol A, with removal efficiency being as high as $75 \%$ in less than $24 \mathrm{~h}$. The adsorption process is characterized by a fast-initial rate which tends to reduce progressively, and follows a pseudo second order model equation. Statistical physical analysis allows for obtaining a molecular description of the adsorption, which is shown to take place through a single anchorage point, perpendicularly to the adsorbent surface. Nuclear magnetic resonance spectroscopy and florescence analysis reveal that the colloidal organic matter released from the cork interacts with Bisphenol A; it also plays a relevant role in the slowing down of the adsorption rate, as it competes with cork adsorption sites for Bisphenol A. Organic matter is found to be highly heterogenous, presenting at the same time carbohydrates, aromatic and aliphatic domains. Such moieties interact stably with the contaminant in the solution probably due the establishment of dispersive forces (e.g. $\pi$-stacking) which sequestrate Bisphenol A into the inner hydrophobic core of the organic matter three-dimensional structure.
\end{abstract}

Keywords: adsorption; Bisphenol A; cork; emerging contaminant; organic matter 


\section{Introduction}

The occurrence of emerging or newly identified contaminants in wastewater is one of the greatest concerns for the health and safety of exposed humans (Bolong et al., 2009). The majority of these contaminants are generally not regulated by threshold limits and in many cases their potential toxic and/or carcinogenic effects, as well as their fate in aquatic systems, are yet to be completely understood (Richardson and Kimura, 2016). Bisphenol A (BPA) is a very representative example of this issue, as for many years BPA has been considered as an innocuous compound, and has been largely used in numerous industrial applications including the manufacturing of every-day use objects, such as some food and drink containers.

Nowadays its potential adverse effect on human health and wildlife conservation has been well assessed, and BPA has been included in the class of endocrine-disrupting compounds, i.e. those molecules which have the unique ability (due to their specific structure) to mimic or block natural hormones. Although many doubts still persist concerning the level of safety of BPA (Kovacic, 2010; Michałowicz, 2014), the EU Commission recently has adopted a new and more restrictive regulation (2018/13) on its use for food and beverage containers, clearly indicating the concern existing toward the diffusion of BPA-containing materials.

At the same time many efforts, even at plant scale (Ávila et al., 2015; Schaar et al., 2010), are continuously dedicated to investigate the treatment processes able to remove BPA from wastewater e.g. using ultrasonic waves and hydrogen peroxide (Nikfar et al., 2016), and waste ash (Qasemi et al. 2018), reducing the risk of its uncontrolled discharge in natural environmental compartments . Among others, adsorption seems to be one of the most promising alternatives because of its good efficiency, coupled with its higher simplicity and adaptability compared to the other proposed systems (Hartono et al., 2015). While numerous adsorbents have been tested to remove BPA from aqueous solutions-(Bhatnagar and Anastopoulos, 2017), no attempt has been made so far to use natural cork, which has been proven to be extremely 
efficient towards organic emerging contaminants, such as pyrethroids fenpropathrin, permethrin, deltamethrin, fenvalerate, 1-cyhalothrin, bifenthrin and a-cypermethrin, volatile phenols, paracetamol, chloroanisoles and polycyclic aromatics (Pintor et al., 2012).

Cork is the outer bark of the oak tree (Quercus suber L.), a slow growing, evergreen oak that flourishes only in specific climate regions in the Western Mediterranean (e.g., Spain, Portugal, Southern France, Italy, and Northern Africa), China and Brazil. The chemical composition of cork consists primarily of suberin (Graça, 2015) and lignin (Nikafshar et al., 2017), with the other organic constituents being polysaccharides (cellulose and hemicellulose) and extractives (waxes and tannins) (Silva et al., 2005). Lignin and suberin are natural organic polymers of heterogeneous structure characterized by the presence of aromatic alcohols (monolignols) and acids (i.e. cinnamic and ferulic acid). Suberin is richer in aliphatic substances bound to the aromatic domain as triacyl glycerol esters, and hence, is more hydrophobic (Graça, 2015). The interaction of cork with organic compounds, which are essentially hydrophobic, is determined by its structure, especially by the aromatic domain of suberin and lignin (Pintor et al., 2012). Being hydrophobic itself, cork has an advantage of affinity over other natural materials for the removal of organic pollutants (Domingues et al., 2005). Moreover, the hydrophobic regions in suberin and lignin are expected to increase the ability of hydrophobic compounds to diffuse into cork (Fomina and Gadd, 2014).

Starting from these premises, the current work intends to evaluate the possible use of cork for the removal of BPA from aqueous solution, investigating the mechanism of sorption at both macro- and micro-level, and considering the possible interference of dissolved organic matter (DOM) released by the biosorbent. Recent investigations (Chen et al., 2015; Pontoni et al., 2019; Pontoni et al., 2016b) have demonstrated that DOM may have a fundamental role in the fate of contaminants existing in the aqueous solution at trace level (i.e. emerging contaminants), as they strongly interact with them, subjecting the contaminant to the actions of other 
components present at higher concentrations in the same solution. The study is conducted at laboratory scale, using deionized water, to exclude the possible effect of compounds other than BPA, cork, and cork released components.

\section{Materials and Methods}

\subsection{Materials}

Virgin natural cork was provided in $8 \mathrm{~cm}$ strips from a cork tree located in Goiás State (Brazil). Before use, the strips were cut into small pieces and mechanically grinded (Olivella et al., 2011); the obtained grains were sieved at $2 \mathrm{~mm}$ and washed with deionized (DI) water in a rotary shaker for $97 \mathrm{~h}$, to remove impurities released from the material. The cleaned natural cork $(\mathrm{CNC})$ was then dried at $60^{\circ} \mathrm{C}$ for $24 \mathrm{~h}$. The micromorphologies and compositions of the CNC were investigated using scanning electron microscopy (SEM) at different magnifications on a JEOL JSM-6480LV high-performance, variable pressure analytical scanning electron microscope with secondary electron imaging (SEI), and energy dispersive x-ray spectroscopy (EDS) with an accelerating voltage of $15 \mathrm{kV}$. Individual particles were mounted rigidly on a specimen stub and coated with an ultrathin layer of gold.

BPA stock solution $\left(50 \mathrm{mg} \cdot \mathrm{L}^{-1}\right)$ was obtained dissolving $25 \mathrm{mg}$ of high purity product (> 97\%), purchased from Alfa Aesar (Germany), in $500 \mathrm{~mL}$ of DI water. The solution was continuously stirred at room temperature for about $72 \mathrm{~h}$ to ensure the complete dissolution of the compound. Chemicals used for all analytical determination were ACS grade or better. Before use, glassware was soaked overnight in a diluted nitric acid (2\%) bath and rinsed several times with DI water. Only ultrapure water was used as reagent water, as well as for all required dilutions.

\subsection{Adsorption experiments}


Adsorption experiments were carried out in batch, at laboratory scale and room temperature, using $80 \mathrm{~mL}$ volume reactors, placed in a rotary shaker at $30 \mathrm{rpm}$. In order to ensure a uniform and complete contact between the adsorbent and the contaminant, cork granules were placed in a metal tea infuser strainer, which was able to hold the adsorbent in the center of the reactor.

Kinetic tests were conducted on a $50 \mathrm{ppm}$ BPA solution with the amount of adsorbent varied from 0.05 to $0.6 \mathrm{~g}$, and each test lasted $30 \mathrm{~h}$. At selected times small aliquots of solution were sampled and analyzed for the residual BPA concentration. Further tests were carried out using $0.05 \mathrm{~g}$ of $\mathrm{CNC}$ varying the BPA concentration from 10 to $50 \mathrm{ppm}$, these samples were collected and analyzed only $24 \mathrm{~h}$ after the end of the tests.

The tests were duplicated in order to reduce experimental errors. Blank tests, either with no adsorbent or with no BPA, were run, to take into account the eventual adsorption operated by the reactor or by the strainer, and the release of substances from the adsorbent, that could cause interference within BPA determination.

BPA concentration was detected measuring the absorbance at $276 \mathrm{~nm}$ of withdrawn samples with a M550 Double Beam Scanning UV-Visible Spectrophotometer (SpectronicCamspec, UK). The UV spectrum of BPA in solution is shown in Figure S.1 (Supplementary Information).

\subsection{Characterization of DOM from natural cork}

Water used for cork washing was filtered through $1.5 \mu \mathrm{m}$ (washing water 1, WW1), and carefully analyzed to characterize the DOM from the natural cork. For this small aliquots of the washing water were filtered through $0.45 \mu \mathrm{m}$ (WW2), and $0.2 \mu \mathrm{m}$ (WW3), and subject to COD determination (APHA, 1998) and three dimensional excitation emission matrix (3DEEM) spectrofluorometer. Additional 3DEEM spectra were acquired for: (i) a washing water sample 
filtered only through $0.45 \mu \mathrm{m}$; (ii) a washing water sample filtered only through $0.45 \mu \mathrm{m}$, containing $10 \mathrm{ppm}$ of BPA; and (iii) a solution of $10 \mathrm{ppm}$ BPA in DI water. 3DEEM was acquired by means of a FP750 (Jasco, Japan) spectrofluorometer. The excitation wavelength was varied between 200 and $500 \mathrm{~nm}$, and emission between 280 and $570 \mathrm{~nm}$. Data were processed by the software SPEKWIN 32.

The remaining washing water was freeze-dried (FD) with the help of an alpha 2-4 plus machine (Martin-Christ, Germany), and divided into two aliquots: FD1 and FD2. FD1 was dissolved in $\mathrm{D}_{2} \mathrm{O}$ and subjected to NMR spectroscopy, acquiring ${ }^{1} \mathrm{H}-\mathrm{NMR}$ and ${ }^{13} \mathrm{C}-\mathrm{NMR}$ mono-dimensional spectra using Ascend $400 \mathrm{MHz}$ NMR spectrometer (Bruker, Germany) equipped with BBO broad band smart probe. The probe was set to a temperature of $310 \mathrm{~K}$ to minimize the carbohydrate signals overlapping with the water and to favor the molecular disassembly of polymers (Duus et al., 2000). Edited HSQC bidimensional spectra were also acquired, using a matrix $\left(t_{1} \times t_{2}\right)$ of $1024 \times 128$ points and transformed into a matrix of $4096 \times 2048$ points by means of pure cosine squared sine window function. Data processing was performed using the software Topspin .3.5 from Bruker (Germany). All acquired spectra were calibrated adding trimethylsilyl propanoic acid $\mathrm{d}_{4}$ (Acros organics, Belgium) as internal standard.

Additional ${ }^{1} \mathrm{H}-\mathrm{NMR}$ spectra were acquired for a $20 \mathrm{ppm}$ BPA solution, increasing DOM concentration. Spectra were acquired again at $310 \mathrm{~K}$ by the combination of 256 scans. In this case, water suppression was achieved by using standard pre-saturation pulse sequence.

FD2 was subjected to chemical derivatization prior to gas chromatography-mass spectrometry (GC-MS) analysis. The adopted reaction was the acetylation of methyl glycosides (AMG) (Ruiz-Matute et al., 2011), widely applied in carbohydrate analysis. The reaction, consisting in the acid catalyzed cleavage of glycoside bonds of polysaccharides by means of methanol (Dell, 1990), resulted in the production of methyl glycosides of the monosaccharides composing the 
carbohydrate polymers, which were fully acetylated (AMG) to become less polar and more volatile. The overall procedure included a methanolysis and an acetylation step.

In detail, $1.55 \mathrm{mg}$ of freeze-dried cork water extract was left in a Pyrex tube for $0.5 \mathrm{~h}$ under vacuum, in a desiccator to remove adsorbed water and grant anhydrous conditions for the methanolysis reaction. $0.55 \mathrm{mg}$ of pure myo-inositol (Sigma - Aldrich, Germany) was added as internal standard. Thereafter, the sample was treated with $2 \mathrm{~mL}$ of $\mathrm{MeOH} / 1 \mathrm{M} \mathrm{HCl}$ at $85^{\circ} \mathrm{C}$ in a thermostatic block overnight. The methanolized sample, brought to dryness under compressed nitrogen flow, was washed with $1 \mathrm{~mL} \mathrm{MeOH}$ (Romil, UK) and dried again a number of times until reaching a neutral $\mathrm{pH}$. The sample was left again for $30 \mathrm{~min}$ in the desiccator, and then acetylated with $50 \mu \mathrm{L}$ of pyridine (Sigma-Aldrich, USA) and $50 \mu \mathrm{L}$ of acetic anhydride (SigmaAldrich, USA) for $45 \mathrm{~min}$ at $85^{\circ} \mathrm{C}$ under magnetic stirring. When evaporated to dryness, it was extracted in $\mathrm{CHCl}_{3}$ (Carlo Erba Reagenti, Italy) and $\mathrm{H}_{2} \mathrm{O}$, by washing with water three times. The organic phase was dried under flow of compressed nitrogen and finally the sample was dissolved in $40 \mu \mathrm{L}$ acetone (Romil, UK) and injected to the GC-MS. GC-MS used was a 6850gas chromatograph (Agilent, USA) coupled with a GCT oa-TOF high resolution mass detector (Micromass, UK). The GC was equipped with a ZB-Semi-Volatile Guardian capillary column (Phenomenex, USA). The injector was set in split mode with a split ratio of 10 and the temperature of the liner was set at $230^{\circ} \mathrm{C}$. A thermal program of the column oven was set as follows: $150^{\circ} \mathrm{C}$, hold $3 \mathrm{~min}, 300^{\circ} \mathrm{C}$ at $3^{\circ} \mathrm{C} / \mathrm{min}$, hold $20 \mathrm{~min}$. Obtained peaks were identified comparing the mass spectra with the NIST 98 library, and the retention times with those of reference compounds.

\section{Results and discussion}

\subsection{Cork characterization}


SEM image of natural cork granules (Figure 1) showed an alveolar structure, analogous to that of a honeycomb, with no empty spaces between contiguous cells, which appeared to be as closed units. The prismatic hollows cells presented a diameter of about 30-40 $\mu \mathrm{m}$, therefore, constituting of macropores (> $50 \mathrm{~nm}$ according to IUPAC). Additionally, no internal porosity was apparent. Elemental analysis revealed, as expected, that carbon was the main constituent of cork granules, representing the base of structural components (suberin, lignin, polysaccharides and extractives). Hydrogen was the counterpart of carbon in the aliphatic chains of suberin and aromatic rings of lignin. Finally, nitrogen content was associated to minor extractives and peptic polysaccharides in the cell wall. Impurities of $\mathrm{Si}, \mathrm{S}, \mathrm{Cl}$, and $\mathrm{K}$ were also found.
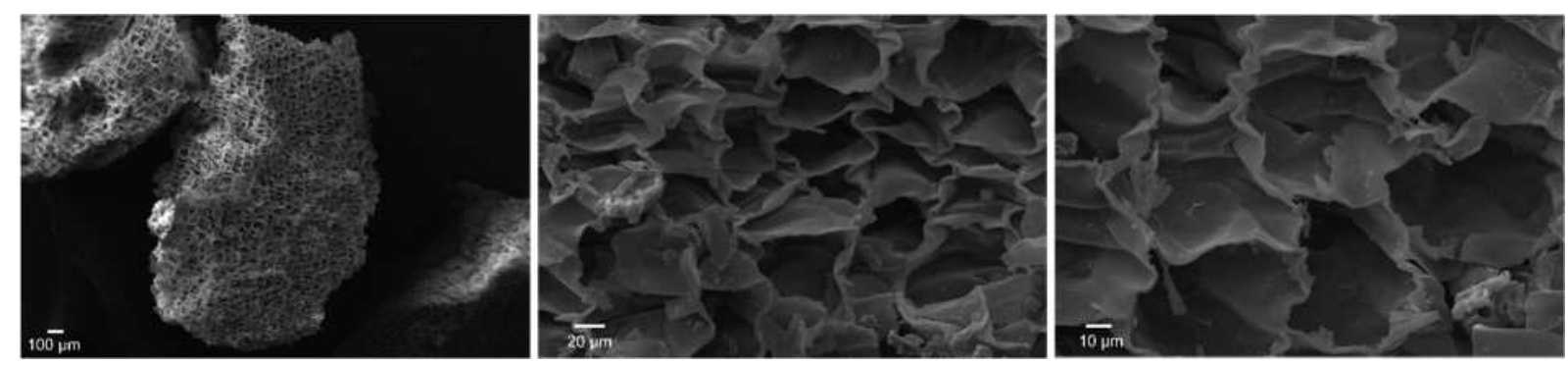

Figure 1: SEM images at different magnifications of natural cork granules

\subsection{Adsorption batch tests}

The results of the adsorption experiments are summarized in Figures 2 and 3. Although the removal capacity was lower than the one obtained using commercial activated carbon, it was higher compared to many other bio-sorbents (Table S1) The kinetic tests (Figure 2) revealed that cork was able to remove from $10 \%$ to $54 \%$ of BPA in $5 \mathrm{~h}$, and reached a total removal efficiency ranging between $17 \%$ and $75 \%$ in about $24 \mathrm{~h}$ (Figure $2 \mathrm{a}$ ). The efficiency was greatly improved through increasing the amount of used cork, although the amount of BPA adsorbed per gram of $\mathrm{CNC}$ decreased at higher dosages of the adsorbent, indicating that the total capacity of available adsorption sites was not fully saturated. At the same time a slow 
release of organic matter was observed in terms of absorbance from $\mathrm{CNC}$ over time, despite the described washing procedure (Figure $2 b$ ).
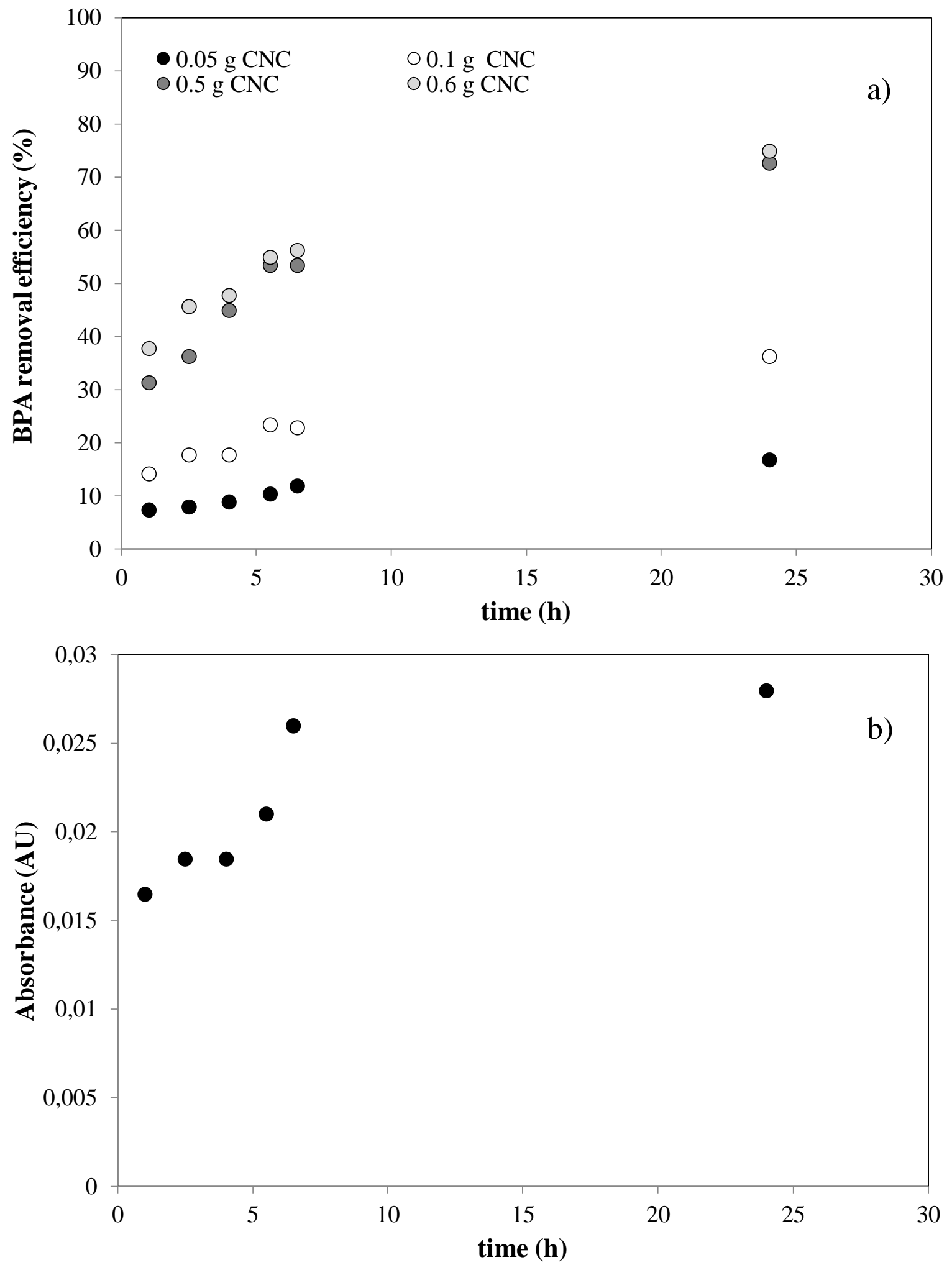

Figure 2: a) Results of kinetic tests varying adsorbent dose, b) Release of organic matter from CNC over time $(80 \mathrm{~mL}$ DI water $+0.05 \mathrm{~g}$ CNC) measured as absorbance at $274 \mathrm{~nm}$ 
As often in case of biosorption processes (Fabbricino and Gallo, 2010; Fabbricino and Pontoni, 2016; Wang and Chen, 2009) the adsorption capacity was characterized by an initial fast removal rate, which tended progressively to an important reduction. Experimental data could be best fitted by a pseudo second order model equation $\left(R^{2}>0.98\right)$, represented by Equation (1):

$\frac{t}{q_{t}}=\frac{1}{\left(k_{1} \cdot q_{e}^{2}\right)}+\frac{t}{q_{e}}$

where:

$\mathrm{t}=$ time $(\mathrm{h})$

$\mathrm{q}_{\mathrm{t}}=\mathrm{BPA}$ removed at time $\mathrm{t}\left(\mathrm{mg} \cdot \mathrm{g}^{-1}\right)$

$\mathrm{q}_{\mathrm{e}}=$ BPA removed at equilibrium conditions $\left(\mathrm{mg} \cdot \mathrm{g}^{-1}\right)$

$\mathrm{k}_{1}=$ kinetic constant $\left(\mathrm{mg} \cdot \mathrm{g}^{-1} \cdot \mathrm{h}^{-1}\right)$

It was therefore supposed that the process was governed by chemical reactions, which included electron sharing and/or exchange between the adsorbent and the adsorbate (AbdelGhani et al., 2016; Fabbricino et al., 2013; Ho, 2006). 

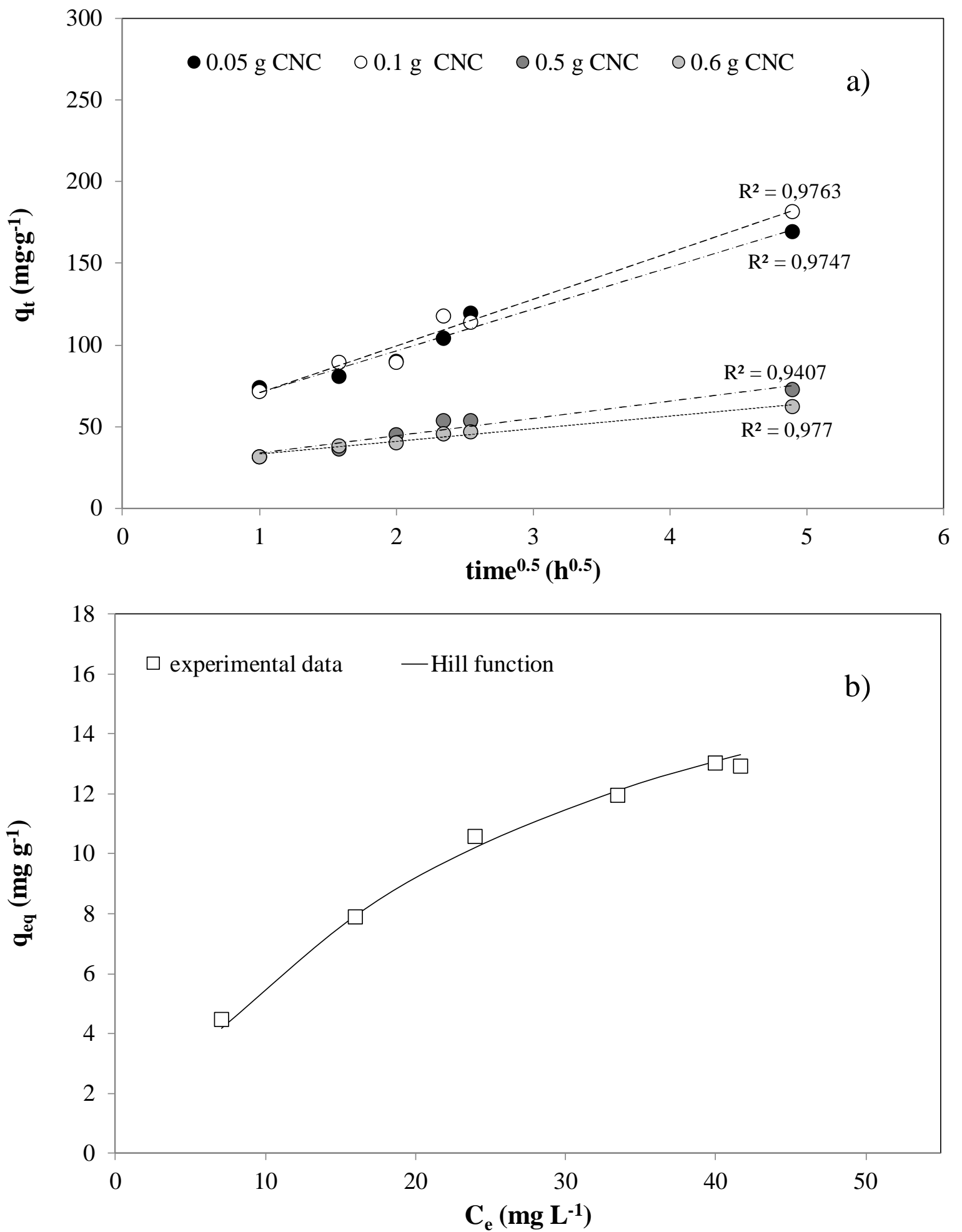

Figure 3: a) Webber-Morris plot; b) Isotherm curve: $q_{e q}=$ adsorbed BPA per unit mass of CNC; $C_{e}=$ concentration of BPA in the solution at equilibrium

For a more detailed analysis of the phenomenon, a mechanistic description of the results was attempted, analyzing the role of diffusion processes. For this, the Weber-Morris representation of data (Figure 3a) was adopted, based on Equation (2): 
$\mathrm{q}_{\mathrm{t}}=\mathrm{k}_{\mathrm{d}} \cdot \mathrm{q}_{\mathrm{e}}^{2}+\mathrm{k}_{\mathrm{b}}$

where:

$\mathrm{k}_{\mathrm{d}}=$ diffusion rate constant $\left(\mathrm{mg} \cdot \mathrm{g}^{-1} \cdot \mathrm{h}^{-0.5}\right)$

$\mathrm{k}_{\mathrm{b}}=$ boundary layer effect constant $\left(\mathrm{mg} \cdot \mathrm{g}^{-1}\right)$

Obtained plots indicated that the data could be fitted by straight lines, having positive intercepts. The result corresponded to an adsorption process governed by diffusion, taking place in two successive steps, corresponding to an initial diffusion towards CNC surface and successive intraparticle diffusion into the CNC pores. The mechanistic description was in agreement with the observed structure of the adsorbent (Figure 1). Further information on the adsorption mechanism at molecular level was obtained by adopting a statistical physical approach (Fabbricino and Pontoni, 2016; Franco et al., 2015; Khalfaoui et al., 2002b). As it could be easily seen in the analysis of the isotherm (Figure $3 b$ ) that the experimental points were perfectly aligned on a concave curve; this presented a single downward concavity with no inflection points. Such a trend, characteristic of Type I isotherms according to the classification of Brauner, Ermett and Teller (Khalfaoui et al., 2003), indicated a monolayer adsorption process. It could then be assumed (Khalfaoui et al., 2003) that each adsorption site was either occupied by a single molecule of BPA or empty (Khalfaoui et al., 2002a). The grand canonical function used for the statistical physical approach (Dotto and Pinto, 2011; Dotto et al., 2015; Fabbricino and Pontoni, 2016; Khalfaoui et al., 2002b; Khalfaoui et al., 2012) was therefore written in the simplified Hill form: 


$$
\mathrm{m}_{\mathrm{BPA}} \cdot \mathrm{N}_{\mathrm{a}}=\frac{\mathrm{n}_{\mathrm{BPA}} \cdot \mathrm{m}_{\mathrm{BPA}} \cdot \mathrm{N}_{\mathrm{M}}}{\left[1+\left(\frac{\mathrm{C}_{0.5}}{\mathrm{C}_{\mathrm{e}}}\right)^{\mathrm{n}_{\mathrm{BPA}}}\right]}
$$

where:

$\mathrm{m}_{\mathrm{BPA}}=$ molecular weight of BPA

$\mathrm{N}_{\mathrm{a}}=$ number of adsorbed BPA molecules

$\mathrm{n}_{\mathrm{BPA}}=$ number of adsorbed BPA molecules per available adsorbent site

$\mathrm{N}_{\mathrm{M}}=$ receptor site density $\left(\mathrm{mg} \cdot \mathrm{g}^{-1}\right)$

$\mathrm{C}_{0.5}=$ half saturation BPA concentration $\left(\mathrm{mg} \cdot \mathrm{L}^{-1}\right)$

Numerical values for the model parameters were obtained by fitting the experimental data of Figure 3, resulting in $\mathrm{n}_{\mathrm{BPA}}=1,1$ and $\mathrm{N}_{\mathrm{M}}=19$. The efficiency of the model (Ferraro et al., 2016) and the regression coefficient were both > 0.99 indicating a very good fit.

The steric interpretation of Hill's parameters provided the required overview of the phenomenon at molecular level. The anchorage number, equaling the reciprocal of the number of adsorbed molecules per site, resulted as 0.90 . At the same time the steric hindrance, directly related to the receptor site density, was positive and $>10$. It could be concluded that BPA molecules presented a single anchorage point, and therefore the adsorbed molecules were perpendicular to the adsorbent surface. Because of the elevated hindrance, such a configuration precluded the possibility of using the adsorption sites close to the anchorage points, reducing the total obtained efficiency. The chemical structure of BPA only partially explained the hindrance effect. Such evidence together with the observation that the CNC was still releasing something into the water phase (Figure 2b) suggested the possibility of an aggregation of the molecule with the organic substances released by the CNC. 


\subsection{Characterization of DOM released from cork}

In order to better clarify the adsorption mechanisms of BPA onto the $\mathrm{CNC}$, and to better understand the encountered steric hindrance, the role of the organic matter released by the cork was investigated, through a detailed analysis of the washing water.

COD of WW1, WW2 and WW3 was found as $57.4,51.9$ and $41.9 \mathrm{mg} \cdot \mathrm{L}^{-1}$, respectively. The slight decrease of COD with the pore size of filters used to obtain the samples indicated that the main contribution to the released organic compounds was due to the smallest solid fractions contained in both dissolved and colloidal form.
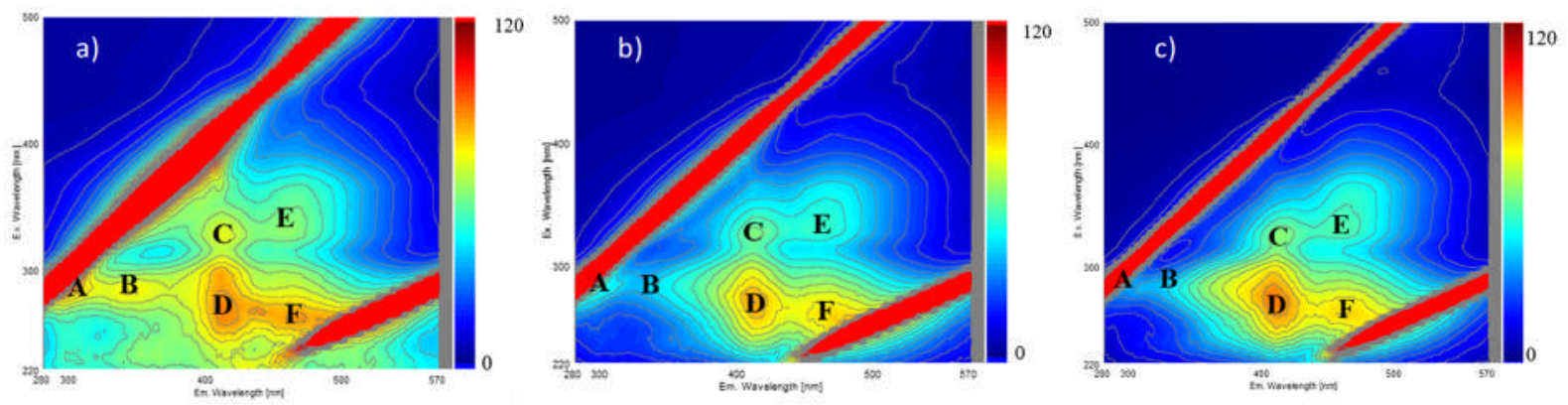

Figure 4: Fluorescence 3DEEM of: a) WW1; b) WW2; c) WW3

In accordance with the COD values fluorescence intensity decreased with decreasing the pore size (Figure 4). Several differences were noted in the 3DEEM spectra of the samples. The peaks indicated as A (ex 280 - em $310 \mathrm{~nm}$ ) and B (ex 280 - em $350 \mathrm{~nm}$ ), related to Tyrosine and Tryptophan-like fluorophores (Yamashita and Tanoue, 2003) usually constituting the primary structure of proteins, were observable only for WW1 and with much lower intensity for WW2. The identified protein residues were reasonably attributable to the release of vegetal cells fragments from cork (fraction between 1.5 and $0.45 \mu \mathrm{m}$ ). However, it is suggested to confirm these by spiking standard Tyrosine and Tryptophan into the WW1. Peaks indicated as C (ex 320 em - 410 - nm), D (ex 270 em - 410 nm), E (ex 340 - em 470) and F (ex 260 - em $470 \mathrm{~nm}$ ) were common to all samples, and were therefore, due to molecules smaller than 0.2 $\mu \mathrm{m}$. In detail, as suggested by Chen et al. (2003), peaks E and F were attributed to the presence 
of humic substances (Yamashita and Jaffé, 2008). However, peaks C and D were attributed to colloidal carbohydrates, in agreement with the observation of Kalita et al. (2015a and b) who reported that cellulose nanofibers with high crystallinity expresses very high fluorescence at various excitation wavelengths with a maximum of emission at $404 \mathrm{~nm}$.

Results of GC-MS chromatography performed on FD2 samples (Figure 5) allowed identifying several components (S.I., Table S2). A variety of pentoses, mainly xylose, was observed at low retention times (between 8 and $10 \mathrm{~min}$ ), together with a 6 deoxy hexose (Rhamnose). Glucose, mannose and galactose (hexoses) were also identified between 16 and 17 min. The overall carbohydrate composition together with the relative concentrations (Table S2) were compatible (high amount of xylose - i.e. $105 \mathrm{mg} \cdot \mathrm{g}^{-1}$ ) with the composition of hemicellulose commonly found to be extractable from cork (Pereira, 2015; Silva et al., 2005). The presence of fatty acids at retention time 10:25 and 15:82 min was observed too.

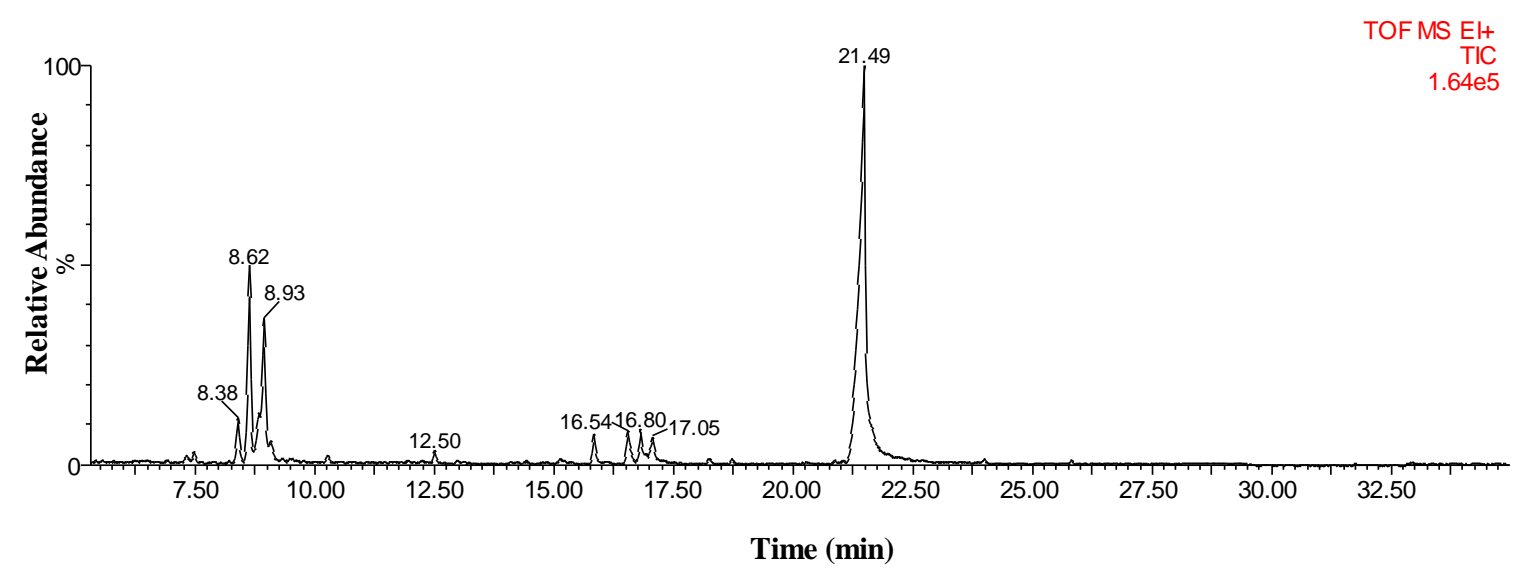

Figure 5: Chromatograph of the AMG of the organic matter released from cork 


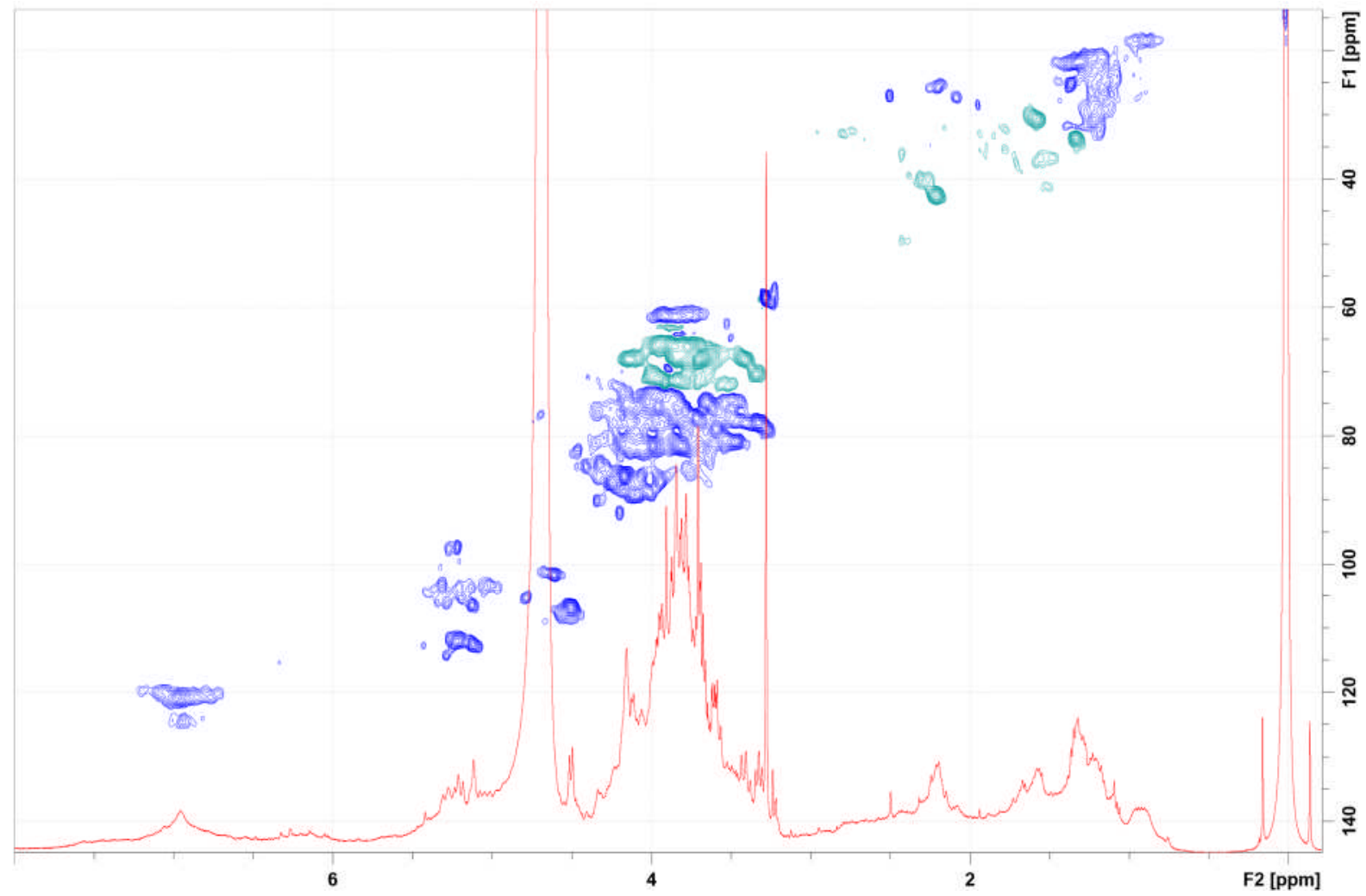

Figure 6: ${ }^{1} \mathrm{H}$ NMR spectrum of DOM (red line); ${ }^{1} \mathrm{H}-{ }^{13} \mathrm{C} \mathrm{HSQC} \mathrm{edited} \mathrm{(} \mathrm{CH}, \mathrm{CH}_{3}$ blue, $\mathrm{CH}_{2}$ green contours

NMR spectroscopy performed on FD1 sample (Figure 6) confirmed the results of GCMS analysis. The NMR spectrum was characterized by a wide distribution of peaks through the entire range of chemical shifts comprised between 1 and $8 \mathrm{ppm}$. The released organic matter was highly heterogenous and an exhaustive characterization of each of its components was behind the scope of the present work. Nevertheless, useful information was obtainable from the HSQC experiment.

In detail it was possible to observe several cross peaks attributable to anomeric $\mathrm{C}-\mathrm{H}$ correlations and hence attributable to both $\alpha\left(5.5>{ }^{1} \mathrm{H}-\delta>5.0 ; 96>{ }^{13} \mathrm{C}-\delta>94\right)$ and $\beta\left(5.0>{ }^{1} \mathrm{H} \delta>4.2\right.$; $\left.104>{ }^{13} \mathrm{C}-\delta->100\right)$. The cross peaks observed at low fields are related to the presence of aromatic C-H correlations $\left(7.2>{ }^{1} \mathrm{H}-\delta>6.7 ; 130>{ }^{13} \mathrm{C}-\delta>120\right.$ ) (Yuan et al., 2011) and of styrene like conjugated system (i.e. cinnamic acid-like) $\mathrm{CH}$ correlations $\left(5.5>{ }^{1} \mathrm{H}-\delta>5 ; 116>{ }^{13} \mathrm{C}-\delta>110\right)$. The latter HSQC correlation in cork extracts was attributed by Marques António et al. (2016) to the 
presence of ferulic acid which is known to compose suberin from cork (Gil et al., 1997). The central region of Figure 6 includes all the carbohydrates ring protons $\left(4.5>{ }^{1} \mathrm{H}-\delta>2.8\right)$ and many $\mathrm{CH}_{2}$ (green contour) signals ascribable to the presence of alcoholic methylene $\left(\mathrm{CH}_{2} \mathrm{OH}\right)$. The high singlet $(\delta=3.299)$ is correlated to $\mathrm{CH}_{3} \mathrm{HSQC}$ resonance at $59.7 \mathrm{ppm}$ and was probably related to O-methyl function compatible with ferulic acid (Marques António et al., 2016; Yuan et al., 2011). The aliphatic region showed both $\mathrm{CH} / \mathrm{CH}_{3}$ and $\mathrm{CH}_{2}$ correlations compatible with the presence of the organic acids also identified by GC-MS and of acetylated hydroxyl and methyl of 6 deoxy sugar (i.e Rhamnose $\delta=1.26$ ) (Roslund et al., 2011). The signal within the

aromatic region in the ${ }^{1} \mathrm{H}$ resonance spectrum was broadened and poorly resolved. Such behavior was related to the presence of three-dimensional structure of the DOM, associated to the sequestration of aromatic substances into the inner hydrophobic core (Pan et al., 2012). It was supposed, in fact, that this structure made the aromatic protons to have different relaxation times (Gil et al., 1997; Lopes et al., 2000), resulting in the observed broad unresolved peaks (Lam and Simpson, 2008; Pontoni et al., 2016a).

\subsection{Evaluation of the interaction of BPA with organic matter in the water phase}

Figure 7 (a,b, and c) shows the comparison between the 3DEEM matrixes in order to evaluate the interaction of BPA with the fluorophores of the colloidal organic matter released by the cork. It was possible to observe that BPA had two intense fluorescence areas (ex 230 em 310; ex 280 - em 310) (Figure 7a). The fluorescence of the organic matter shown in Figure $7 \mathrm{~b}$, was due to humic substances emitted at higher wavelength, and to colloidal carbohydrates with emission maximum around $410 \mathrm{~nm}$. 

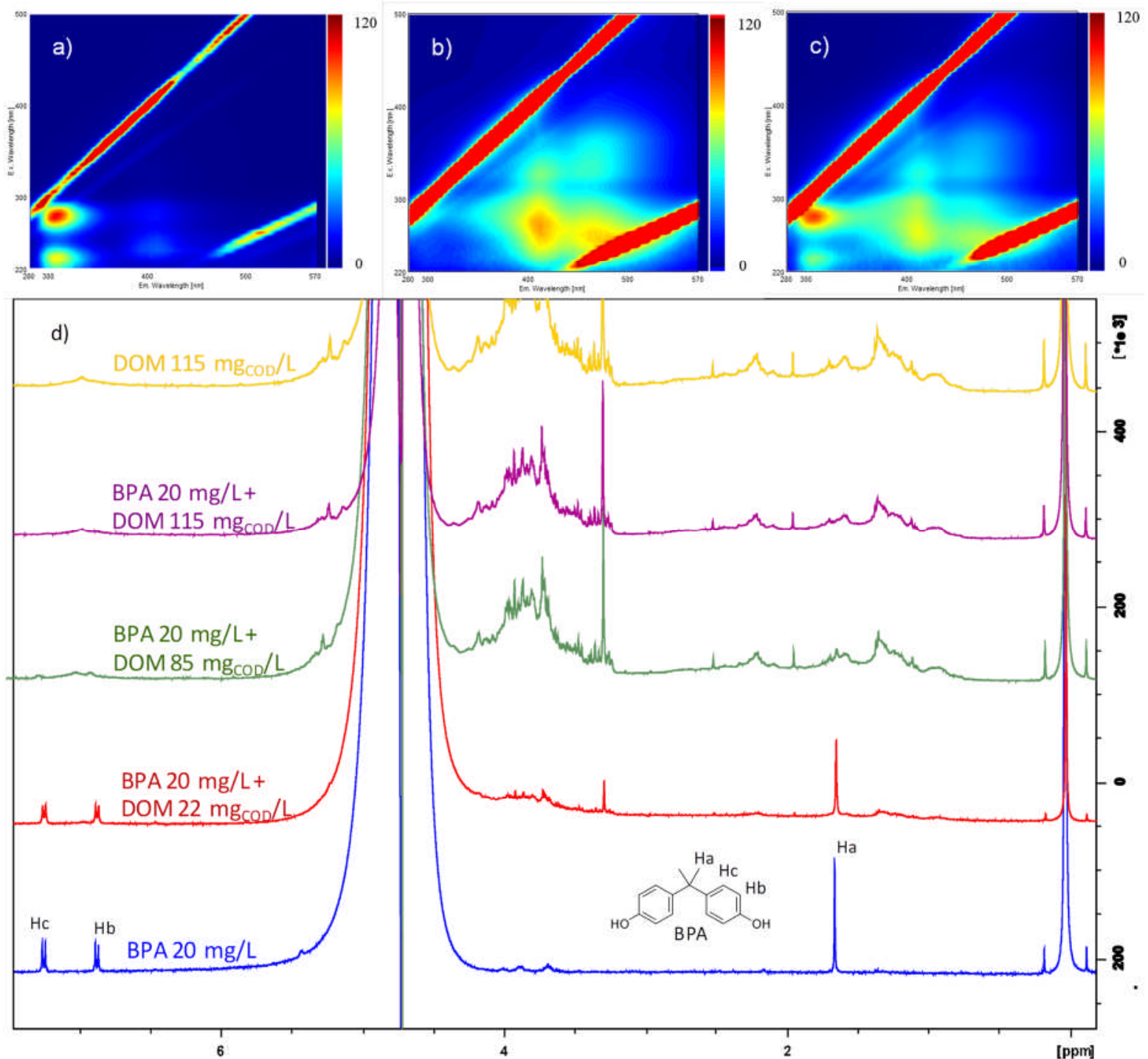

Figure 7: Interaction BPA-DOM: a) Fluorescence of 10 ppm BPA solution; b) Fluorescence of organic matter released form CNC, $0.45 \mu \mathrm{m}$ filtered; $c$ ) Fluorescence of organic matter released form $C N C, 0.45 \mu \mathrm{m}$ filtered + 10 ppm of BPA; d) $1 H$-NMR spectra of BPA at increasing concentration of DOM

It was possible to observe that both carbohydrates and humic substances fluorescence areas were quenched by the presence of 10 ppm BPA (Fig. 7c). In addition, BPA signals were also quenched by themselves. The decrease shown by the intensity of all organic matter signals confirmed that in the water phase BPA interacted with the DOM. The aggregation of organic matter by means of hydrophobic interactions reduced the fluorescence intensity due to the deenergizing of the excited molecules, occurring through a charge transfer mechanism to the 
neighbour organic molecules (Hernandez-Ruiz et al., 2012; Mousset et al., 2013; Wang et al., 2015).

The red shift of fluorescence shown in Figure 7c was linked to the formation of excimers (temporary dimers), having lower energy compared to the excited monomer, which became favored when the fluorophores were close to each other (Kumacheva et al., 1997). The interaction observed by the discussed fluorescence quenching was confirmed by the complete disappearance of the BPA signals when increasing the DOM concentration into the ${ }^{1} \mathrm{H}$ NMR spectra (Figure 7d). As previously discussed, the aggregation of substances into hydrophobic cores or micelles created a different chemical surrounding for the resonating protons. This reflects into different relaxation times which finally implies a severe loss of resolution of the spectra. The only explanation for the observed disappearance of BPA signals is that they were sequestrated from the water phase and aggregated within the inner of the DOM hydrophobic core.

Such interaction is enforced by the establishment of $\mathrm{T}$ shape $\pi$ stacking interactions between the aromatic planes of phenol-like and hydroxybenzoic acid-like DOM moieties (Zhu et al., 2012). In the actual case it is easy to hypothesize the same kind of interaction with ferulic acid like residues. It follows the gradual loss of signal when increasing the DOM/BPA concentration ratio into the solution which is related to the different relaxation time of BPA signals once complexed to DOM (Lam and Simpson, 2008). Moreover, the establishment of $\pi$ stacking interaction contributes to change the relaxation time (Parenti et al., 2017), and chemical shifts also broaden due to anisotropic shielding (Platts and Gkionis, 2009). Such phenomenon was observed at a very high rate compared to the absorption kinetics, since all the spectra were acquired just few minutes after the composition of the solutions. The spectra acquired with a DOM concentration of $115 \mathrm{mg} C O D \cdot \mathrm{L}^{-1}$ were identical in presence or absence 
of BPA, (Figure 7d, purple and yellow lines) as if the contaminant had never been added to the solution.

\subsection{CNC-BPA adsorption mechanism hypothesis}

Considering the interaction between the organic matter released from the $\mathrm{CNC}$ and $\mathrm{BPA}$, the adsorption mechanism for the removal of BPA by the CNC could be further elucidated. The released organic matter interacting with the BPA competed with cork active sites, slowing the adsorption rate. As the release of organic matter increased with the time (Figure 2b), BPA uptake was not influenced by the release phenomenon during the first stage but only during the second one, when the release became significant.

During the first stage of the process, BPA was rapidly adsorbed onto the CNC surface by chemical forces. When the concentration of dissolved organic matter became significant, the DOM sequestrated the BPA present in the solution, establishing fast (within minutes) hydrophobic interaction between BPA and DOM. The adsorption process then resulted in being controlled kinetically by the release of organic matter. In this case the BPA decrease in water was related to the adsorption/desorption slow equilibrium existing between the solid phase and the DOM. Here we hypothesise that the BPA+DOM complex adsorption might be related to the concentration of DOM, and this is in good agreement with the second order kinetics. This would also explain either the intra particle diffusion or the steric hindrance encountered, since the BPA+DOM complexes could have dimensions comparable to the cork pores ones. Nevertheless, further investigation is needed for a deeper understanding of the mechanism.

\section{Conclusions and future perspectives}

Batch adsorption experiments for the removal of BPA from aqueous solutions were carried out using cleaned natural cork. The adsorption process resulted to be slow and a pseudo- 
equilibrium was reached within $24 \mathrm{~h}$. Adsorption was characterized by a Type 1 isotherm, and the data were well fitted by a pseudo second-order kinetic equation. An intra-particle diffusion model also fitted the dataset and the number of anchorages per site was determined to be 0.90 , confirming the monolayer adsorption. At the same time the steric hindrance, directly related to the receptor site density, was positive and $>10$. During the adsorption experiments the release of DOM into the water phase was observed. A potential interaction between the BPA and the DOM was therefore investigated and confirmed. A very fast and stable interaction was demonstrated between BPA and the DOM released from cork into the water phase. A physicalchemical characterization of the DOM was performed achieving its composition in terms of carbohydrates and highlighting the presence of aromatic and aliphatic compounds.

The kinetics of the process was slowed by the release of the DOM into the water phase. The DOM resulted to compete with the active sites of the CNC, determining a slowdown of the adsorption kinetic. Therefore, it is suggested to develop tests, including pilot scale using natural wastewater to gain further insight on this.

Further investigation is needed for a deeper understanding of the adsorption mechanism in these conditions. The interaction between DOM and BPA occurred when the concentration of DOM was comparable to the concentration of BPA. Reasonably, extrapolating the present work to a real environmental BPA concentration, the interaction with DOM would play a primary role in determining the overall process kinetic and yield. The evaluation of the desorption mechanisms of BPA from cork still needs to be investigated. The possibility of recycling/reusing the spent $\mathrm{CNC}$ adsorbent must be seriously considered in future studies to safeguard the sustainability of the process.

\section{References}


Abdel-Ghani, N.T., Rawash, E.S.A., El-Chaghaby, G.A., 2016. Equilibrium and kinetic study for the adsorption of $\mathrm{p}$-nitrophenol from wastewater using olive cake based activated carbon. Global Journal of Environmental Science and Management 2(1), 11-18.

APHA, W., 1998. AWWA (1998) Standard methods for the examination of water and wastewater. Amer. Pub. Health Association. Washington DC.

Ávila, C., Bayona, J.M., Martín, I., Salas, J.J., García, J., 2015. Emerging organic contaminant removal in a full-scale hybrid constructed wetland system for wastewater treatment and reuse. Ecol. Eng. 80, 108-116.

Bhatnagar, A., Anastopoulos, I., 2017. Adsorptive removal of bisphenol A (BPA) from aqueous solution: A review. Chemosphere 168, 885-902.

Bolong, N., Ismail, A., Salim, M.R., Matsuura, T., 2009. A review of the effects of emerging contaminants in wastewater and options for their removal. Desalination 239(1), 229-246.

Chen, Y., Fabbricino, M., Benedetti, M.F., Korshin, G.V., 2015. Spectroscopic in situ examination of interactions of rare earth ions with humic substances. Water Res. 68, 273281.

Dell, A., 1990. [35] Preparation and desorption mass spectrometry of permethyl and peracetyl derivatives of oligosaccharides, Methods Enzymol. Academic Press, pp. 647-660.

Domingues, V., Alves, A., Cabral, M., Delerue-Matos, C., 2005. Sorption behaviour of bifenthrin on cork. J. Chromatogr. 1069(1), 127-132.

Dotto, G.L., Pinto, L.A.A., 2011. Adsorption of food dyes acid blue 9 and food yellow 3 onto chitosan: Stirring rate effect in kinetics and mechanism. J. Hazard. Mater. 187(1), 164-170.

Dotto, G.L., Pinto, L.A.A., Hachicha, M.A., Knani, S., 2015. New physicochemical interpretations for the adsorption of food dyes on chitosan films using statistical physics treatment. Food Chem. 171, 1-7. 
Duus, J.Ø., Gotfredsen, C.H., Bock, K., 2000. Carbohydrate Structural Determination by NMR Spectroscopy: Modern Methods and Limitations. Chem. Rev. 100(12), 4589-4614.

Fabbricino, M., Gallo, R., 2010. Chromium removal from tannery wastewater using ground shrimp shells. Desalin. Water Treat. 23(1-3), 194-198.

Fabbricino, M., Naviglio, B., Tortora, G., d'Antonio, L., 2013. An environmental friendly cycle for Cr(III) removal and recovery from tannery wastewater. J. Environ. Manage. 117, $1-6$.

Fabbricino, M., Pontoni, L., 2016. Use of non-treated shrimp-shells for textile dye removal from wastewater. J. Environ. Chem. Eng. 4(4, Part A), 4100-4106.

Fomina, M., Gadd, G.M., 2014. Biosorption: current perspectives on concept, definition and application. Bioresour. Technol. 160, 3-14.

Franco, D.S.P., Piccin, J.S., Lima, E.C., Dotto, G.L., 2015. Interpretations about methylene blue adsorption by surface modified chitin using the statistical physics treatment. Adsorption 21(8), 557-564.

Gil, A.M., Lopes, M., Rocha, J., Pascoal Neto, C., 1997. A 13C solid state nuclear magnetic resonance spectroscopic study of cork cell wall structure: the effect of suberin removal. Int. J. Biol. Macromol. 20(4), 293-305.

Graça, J., 2015. Suberin: the biopolyester at the frontier of plants. Frontiers in Chemistry $3(62)$.

Hartono, M.R., Assaf, A., Thouand, G., Kushmaro, A., Chen, X., Marks, R.S., 2015. Use of Bamboo Powder Waste for Removal of Bisphenol A in Aqueous Solution. Water, Air, Soil Pollut. 226(11), 382.

Hernandez-Ruiz, S., Abrell, L., Wickramasekara, S., Chefetz, B., Chorover, J., 2012. Quantifying PPCP interaction with dissolved organic matter in aqueous solution: 
Combined use of fluorescence quenching and tandem mass spectrometry. Water Res. 46(4), 943-954.

Ho, Y.-S., 2006. Review of second-order models for adsorption systems. J. Hazard. Mater. 136(3), 681-689.

Khalfaoui, M., Baouab, M.H.V., Gauthier, R., Lamine, A.B., 2002a. Dye Adsorption by Modified Cotton. Steric and Energetic Interpretations of Model Parameter Behaviours. Adsorpt. Sci. Technol. 20(1), 33-47.

Khalfaoui, M., Baouab, M.H.V., Gauthier, R., Lamine, A.B., 2002b. Statistical Physics Modelling of Dye Adsorption on Modified Cotton. Adsorpt. Sci. Technol. 20(1), 17-31.

Khalfaoui, M., Knani, S., Hachicha, M.A., Lamine, A.B., 2003. New theoretical expressions for the five adsorption type isotherms classified by BET based on statistical physics treatment. J. Colloid Interface Sci. 263(2), 350-356.

Khalfaoui, M., Nakhli, A., Knani, S., Baouab, H.V., Ben Lamine, A., 2012. On the statistical physics modeling of dye adsorption onto anionized nylon: Consequent new interpretations. J. Appl. Polym. Sci. 125(2), 1091-1102.

Kovacic, P., 2010. How safe is bisphenol A? Fundamentals of toxicity: Metabolism, electron transfer and oxidative stress. Med. Hypotheses 75(1), 1-4.

Kumacheva, E., Rharbi, Y., Winnik, M.A., Guo, L., Tam, K.C., Jenkins, R.D., 1997. Fluorescence Studies of an Alkaline Swellable Associative Polymer in Aqueous Solution. Langmuir 13(2), 182-186.

Lam, B., Simpson, A.J., 2008. Direct 1H NMR spectroscopy of dissolved organic matter in natural waters. Analyst 133(2), 263-269.

Lopes, M.H., Sarychev, A., Pascoal Neto, C., Gil, A.M., 2000. Spectral editing of 13C CP/MAS NMR spectra of complex systems: application to the structural characterisation of cork cell walls. Solid State Nucl. Magn. Reson. 16(3), 109-121. 
Marques António, V., Rencoret, J., Gutiérrez, A., del Río José, C., Pereira, H., 2016. Ferulates and lignin structural composition in cork, Holzforschung. p. 275.

Michałowicz, J., 2014. Bisphenol A - Sources, toxicity and biotransformation. Environ. Toxicol. Pharmacol. 37(2), 738-758.

Mousset, E., Oturan, N., van Hullebusch, E.D., Guibaud, G., Esposito, G., Oturan, M.A., 2013. A new micelle-based method to quantify the Tween $80 ®$ surfactant for soil remediation. Agron. Sustain. Dev. 33(4), 839-846.

Nikafshar, S., Zabihi, O., Hamidi, S., Moradi, Y., Barzegar, S., Ahmadi, M., Naebe, M., 2017. A renewable bio-based epoxy resin with improved mechanical performance that can compete with DGEBA. RSC Advances 7(14), 8694-8701.

Nikfar, E., Dehghani, M.H., Mahvi, A.H., Rastkari, N., Asif, M., Tyagi, I., Agarwal, S., Gupta, V.K., 2016. Removal of Bisphenol A from aqueous solutions using ultrasonic waves and hydrogen peroxide. J. Mol. Liq. 213, 332-338.

Olivella, M.À., Jové, P., Oliveras, A., 2011. The use of cork waste as a biosorbent for persistent organic pollutants-Study of adsorption/desorption of polycyclic aromatic hydrocarbons. J. Enviro. Sci. Heal. A 46(8), 824-832.

Pan, B., Liu, Y., Xiao, D., Wu, F., Wu, M., Zhang, D., Xing, B., 2012. Quantitative identification of dynamic and static quenching of ofloxacin by dissolved organic matter using temperature-dependent kinetic approach. Environ. Pollut. 161, 192-198.

Parenti, F., Tassinari, F., Libertini, E., Lanzi, M., Mucci, A., 2017. П-Stacking Signature in NMR Solution Spectra of Thiophene-Based Conjugated Polymers. ACS Omega 2(9), $5775-5784$.

Pereira, H., 2015. The Rationale behind Cork Properties: A Review of Structure and Chemistry. 
Pintor, A.M.A., Ferreira, C.I.A., Pereira, J.C., Correia, P., Silva, S.P., Vilar, V.J.P., Botelho, C.M.S., Boaventura, R.A.R., 2012. Use of cork powder and granules for the adsorption of pollutants: A review. Water Res. 46(10), 3152-3166.

Platts, J.A., Gkionis, K., 2009. NMR shielding as a probe of intermolecular interactions: ab initio and density functional theory studies. Phys. Chem. Chem. Phys. 11(44), 1033110339.

Pontoni, L., Race, M., van Hullebusch, E.D., Fabbricino, M., Esposito, G., Pirozzi, F., 2019. Effect of sodium concentration on mobilization and fate of trace metals in standard OECD soil. Environ. Pollut. 250, 839-848.

Pontoni, L., van Hullebusch, E., Pechaud, Y., Fabbricino, M., Esposito, G., Pirozzi, F., $2016 a$. Colloidal Mobilization and Fate of Trace Heavy Metals in Semi-Saturated Artificial Soil (OECD) Irrigated with Treated Wastewater. Sustainability 8(12), 1257.

Pontoni, L., van Hullebusch, E.D., Fabbricino, M., Esposito, G., Pirozzi, F., 2016b. Assessment of trace heavy metals dynamics during the interaction of aqueous solutions with the artificial OECD soil: Evaluation of the effect of soil organic matter content and colloidal mobilization. Chemosphere 163, 382-391.

Qasemi, M., Afsharnia, M., Zarei, A., Najafpoor, A.A., Salaria, S., Shams, M., 2018. Phenol removal from aqueous solution using Citrullus colocynthis waste ash. Data in Brief, 18, 620-628.

Richardson, S.D., Kimura, S.Y., 2016. Water Analysis: Emerging Contaminants and Current Issues. Anal. Chem. 88(1), 546-582.

Roslund, M.U., Säwén, E., Landström, J., Rönnols, J., Jonsson, K.H.M., Lundborg, M., Svensson, M.V., Widmalm, G., 2011. Complete 1H and 13C NMR chemical shift assignments of mono-, di-, and trisaccharides as basis for NMR chemical shift predictions 
of polysaccharides using the computer program casper. Carbohydr. Res. 346(11), 13111319.

Ruiz-Matute, A.I., Hernández-Hernández, O., Rodríguez-Sánchez, S., Sanz, M.L., MartínezCastro, I., 2011. Derivatization of carbohydrates for GC and GC-MS analyses. J. Chromatogr. B 879(17), 1226-1240.

Schaar, H., Clara, M., Gans, O., Kreuzinger, N., 2010. Micropollutant removal during biological wastewater treatment and a subsequent ozonation step. Environ. Pollut. 158(5), 1399-1404.

Silva, S.P., Sabino, M.A., Fernandes, E.M., Correlo, V.M., Boesel, L.F., Reis, R.L., 2005. Cork: properties, capabilities and applications. Int. Mater. Rev. 50(6), 345-365.

Wang, J., Chen, C., 2009. Biosorbents for heavy metals removal and their future. Biotechnol. Adv. 27(2), 195-226.

Wang, Z., Cao, J., Meng, F., 2015. Interactions between protein-like and humic-like components in dissolved organic matter revealed by fluorescence quenching. Water Res. $68,404-413$

Yamashita, Y., Jaffé, R., 2008. Characterizing the Interactions between Trace Metals and Dissolved Organic Matter Using Excitation-Emission Matrix and Parallel Factor Analysis. Environ. Sci. Technol. 42(19), 7374-7379.

Yamashita, Y., Tanoue, E., 2003. Chemical characterization of protein-like fluorophores in DOM in relation to aromatic amino acids. Mar. Chem. 82(3), 255-271.

Yuan, T.-Q., Sun, S.-N., Xu, F., Sun, R.-C., 2011. Characterization of Lignin Structures and Lignin-Carbohydrate Complex (LCC) Linkages by Quantitative 13C and 2D HSQC NMR Spectroscopy. J. Agric. Food Chem. 59(19), 10604-10614. 
Zhu, F.-D., Choo, K.-H., Chang, H.-S., Lee, B., 2012. Interaction of bisphenol A with dissolved organic matter in extractive and adsorptive removal processes. Chemosphere 87(8), 857-864. 